\title{
Førstegangs generalisert tonisk-klonisk krampeanfall
}

\begin{abstract}
BAKGRUNN Førstegangs generalisert tonisk-klonisk krampeanfall er en hyppig årsak til akuttinnleggelse. Hensikten med denne artikkelen er å gi en oversikt over epidemiologi, etiologi, utredning og behandling av slike anfall.
\end{abstract}

KUNNSKAPSGRUNNLAG Artikkelen er basert på et skjønnsmessig utvalg av engelskspråklige artikler funnet ved søk i PubMed og på forfatternes egne kliniske erfaringer.

RESULTATER Førstegangs generaliserte tonisk-kloniske krampeanfall inndeles i provoserte og uprovoserte. Provoserte anfall forekommer i nær tilknytning til systemiske forstyrrelser, som hypoglykemi eller alkoholabstinens, eller en lokal cerebral affeksjon, slik som hjerneslag eller hodeskade. Ved uprovoserte anfall kan man ikke påvise slike faktorer. Insidensen er på rundt 35/100 000 personår og 50/100 000 personår for henholdsvis provoserte og uprovoserte anfall. Genetisk predisposisjon og livsstil er viktige risikofaktorer for begge typer anfall. Utredningen i sykehus består av grundig anamnese, somatisk og nevrologisk undersøkelse, EKG, standard-EEG og cerebral MR. Ofte gjøres dessuten cerebral CT akutt. Ved provoserte anfall vil behandlingen og residivfaren avhenge av årsaken. Oppstart av antiepileptika etter ett uprovosert anfall kan redusere risikoen for nye anfall, men på lang sikt er det ikke vist noen reduksjon sammenliknet med det å avvente behandling til etter anfall nummer to.

FORTOLKNING Pasienter med førstegangs generalisert tonisk-klonisk krampeanfall er en heterogen gruppe. Grundig utredning er nødvendig for å kunne skreddersy behandlingen og redegjøre for prognosen.

Et førstegangs generalisert tonisk-klonisk krampeanfall er en hyppig årsak til akuttinnleggelse. Episoden er gjerne både skremmende og dramatisk for den det gjelder og for pårørende eller andre som er vitne til anfallet. På sykehuset er det viktig å utrede pasienten for å finne den tilgrunnliggende årsaken og gi best mulig behandling og for å kunne si noe om prognosen, det vil si risikoen for nye anfall. For pasienten kan et slikt anfall få store konsekvenser i dagliglivet, blant annet når det gjelder muligheten for å kunne kjøre bil. Videre skaper det usikkerhet og engstelse for nye anfall, noe som lett fører til begrensninger i livsutfoldelsen (1).

Hensikten med denne artikkelen er å gi en kort oversikt over hvordan slike anfall klassifiseres samt gi noen råd om utredning og behandling av pasienter med førstegangs krampeanfall. Vi bygger på litteratur og egen klinisk erfaring.

\section{Kunnskapsgrunnlag}

Denne artikkelen er basert på søk i PubMed, der vi har benyttet søkeordene "first seizure», «first generalized tonic-clonic seizure og «first GTC seizure». Søkeordene ble først benyttet hver for seg. Deretter ble de enkeltvis kombinert med (AND) ett og ett av følgende søkeord: «risk factors», «epidemiology», «risk of recurrence», «diagnostics», «treatment» og «prognosis». Videre gjorde vi separate søk med «acute symptomatic seizure», «acute symptomatic seizures», «first unprovoked seizure» og «unprovoked seizure». De to sistnevnte ble hver for seg kombinert med (AND) «epidemiology».

Ut fra totalt 1516 treff har vi gjennomgått 49 engelskspråklige artikler. Disse ble valgt ut etter gjennomgang av titler samt abstrakter til dem som ble vurdert som aktuelle. Vi valgte kun å ta med artikler om voksne. Av de 49 gjennomgåtte artiklene har vi inkludert 30 original- og oversiktsartikler som vi vurderte som de mest relevante. Søket hadde ingen begrensninger bakover i tid og ble avsluttet 23.4. 2014. Tre artikler ble hentet fra forfatternes personlige litteraturarkiv. Artikkelen bygger også på våre egne kliniske erfaringer med denne pasientgruppen.

\section{Klassifisering}

Generaliserte tonisk-kloniske krampeanfall defineres som anfall med bilateral symmetrisk tonisk kontraksjon, fulgt av bilaterale kloniske kontraksjoner av somatisk muskulatur, ofte ledsaget av autonome fenomener (2). I de fleste studier av førstegangs toniskkloniske krampeanfall skiller man mellom provoserte og uprovoserte anfall (3).

\section{Provoserte anfall}

Provoserte anfall, også kalt akutte symptomatiske anfall, defineres som epileptiske krampeanfall som kommer som følge av en

\author{
Martha Seim Realfsen \\ martha.realfsen@gmail.com \\ Siri M. Hylleraas Bø \\ Nevroklinikken \\ Akershus universitetssykehus \\ Morten I. Lossius \\ Karl 0. Nakken \\ Spesialsykehuset for epilepsi - SSE \\ Oslo universitetssykehus
}

\section{HOVEDBUDSKAP}

Førstegangs generaliserte tonisk-kloniske krampeanfall inndeles i provoserte og uprovoserte

Inndelingen har betydning for valg av behandling og for vurdering av risikoen for nytt anfall

En grundig utredning er avgjørende for å kunne skreddersy behandlingen til den enkelte pasient 
systemisk forstyrrelse eller i nær tidsmessig relasjon til en cerebral skade (4).

Eksempler på systemiske årsaker til anfall er hypoglykemi, hyponatremi, eklampsi, hypoksi, alkoholabstinens eller bruk av andre rusmidler, høy feber hos barn og bruk av visse legemidler (ramme 1) $(4,5)$.

Eksempler på årsaker til generaliserte tonisk-kloniske anfall som debuterer i tilslutning til (i løpet av første uke) en morfologisk hjerneaffeksjon er hodeskader, hjerneinfarkt, infeksjoner eller annen cerebral inflammasjon eller et intrakranialt inngrep.

Provoserte anfall oppstår typisk kun når den akutte årsaken er til stede (6). Slike anfall inkluderes ikke i definisjonen av epilepsi. Insidensen av provoserte anfall er på rundt 35/100 000 personår (7-9).

\section{Uprovoserte anfall}

Epilepsi foreligger dersom en person har

- hatt minst to uprovoserte anfall med $>24$ timers mellomrom

- hatt ett uprovosert anfall og en risiko for flere anfall som er like stor som dem som har hatt to uprovoserte anfall (dvs. $>60 \%$ )

- har et kjent epilepsisyndrom (10)

Noen eksempler på risikofaktorer under det andre punktet er påvist epileptiform aktivitet på EEG, en strukturell cerebral lesjon vist ved radiologiske undersøkelser eller kjent epilepsi i familien (11).

Uprovoserte anfall krever ingen umiddelbar forutgående hendelse eller noen påvisbar årsak. Ved et uprovosert krampeanfall kan det være en underliggende anfallsgenererende cerebral lesjon som gjør pasienten disponert for gjentatte anfall (3). Riktignok kan det også ved uprovoserte anfall ha vært anfallsprovoserende faktorer, slik som stress eller søvnmangel, men slike faktorer ligger innenfor dagliglivets rammer, dvs. påkjenninger som vi alle stundom utsettes for (12).

Insidensen av uprovoserte anfall er på rundt 50/100 000 personår $(13-17)$ - med en noe høyere forekomst hos barn under ett år og voksne over 65 år (3).

\section{Etiologi}

Genetisk predisposisjon og livsstil er viktige risikofaktorer for førstegangs generaliserte tonisk-kloniske krampeanfall (18). Genetiske faktorer i denne sammenheng vil si at slike anfall har forekommet hos førstegradsslektninger.

En særlig hyppig årsak til provoserte krampeanfall er «rum fits», eller abstinensanfall, dvs. krampeanfall som oppstår de første 1-2 døgn etter opphør av inntak av store mengder alkohol. For disse er det funnet at risikoen for et første generalisert tonisk-klonisk krampeanfall er økt nesten sju ganger sammenliknet med risikoen hos personer som ikke ruser seg (19).

\section{Klinisk ytringsform}

Et førstegangs krampeanfall som fører til sykehusinnleggelse, er som oftest et generalisert tonisk-klonisk anfall $(20,21)$. Slike anfall kan være primært generaliserte, men kan også ha en fokal start som ofte overses.

En grundig sykehistorie gir ofte holdepunkter for at noen av pasientene har hatt andre anfall tidligere som ikke er blitt erkjent som epileptiske fenomener. Eksempler er nattlige frontallappsanfall med hypermotoriske og verbale automatismer, temporallappsanfall med epigastrisk aura, angst, déjà vu-opplevelser eller lukt- eller smaksfornemmelser samt korte episoder med fjernhet (absenser) eller små rykk i kroppen (myoklonier). Slike anfall oppleves som langt mindre dramatiske enn et generalisert tonisk-klonisk krampeanfall.

\section{Differensialdiagnoser}

Det er mange «epilepsiimitatorer«(22). De mest aktuelle differensialdiagnosene ved et enkeltstående tonisk-klonisk krampeanfall er konvulsive synkoper, hyperventilering og psykogene ikke-epileptiske anfall $(3,23)$.

Dersom synkoper varer mer enn 10 sekunder, det gjelder så vel kardiale og ortostatiske som reflekssynkoper, kan det på grunn av cerebral hypoksi oppstå konvulsjoner. Konvulsive synkoper skiller seg fra tonisk-kloniske krampeanfall ved at anfallet varer kortere (30 sek versus 1-2 min), den toniske fasen er mildere, rykningene er ofte ikke-rytmiske eller asynkrone og de postiktale symptomene er mindre uttalte.

Hyperventilasjonsanfall er som oftest assosiert med angst, lufthunger, distale parestesier og eventuelt tilstivning av hender og føtter (karpopedalspasmer).

Psykogene ikke-epileptiske anfall kan likne et generalisert tonisk-klonisk krampeanfall i utformingen, men pasienten kan gå opp i bro (opistotonusstilling) i den toniske fasen, og rykningene er ofte asynkrone og varierer $i$ intensitet over tid. Som regel varer slike anfall lenger enn epileptiske krampeanfall, dvs. over 1-2 minutter.

\section{Utredning}

Når en pasient innlegges etter et førstegangs krampeanfall, er grundig anamnese (med komparentopplysninger) og somatisk og nevrologisk undersøkelse viktig i utredningen.

Blodprøver tas rutinemessig ved innleggelse etter førstegangs krampeanfall med tanke på eventuelle anfallsutløsende faktorer (3). Følgende analyser bør tas: Hb, CRP, leukocytter, blodsukker, elektrolytter, kreatinin, ASAT, ALAT, alkalisk fosfatase,
RAMME 1

Noen årsaker til provoserte førstegangs generaliserte tonisk-kloniske krampeanfall

- Nylig hodeskade, hjerneslag, meningoencefalitt m.m.

- Alkoholabstinens

- Elektrolyttforstyrrelser, f.eks. hyponatremi, hypomagnesemi

- Endokrine forstyrrelser, f.eks. hyper- eller hypotyreoidisme, diabetes mellitus med hyper- eller hypoglykemi

- Lever-, nyre- eller lungesvikt

- Høy feber hos barn

- Prokonvulsive medikamenter, f.eks. klozapin, bupropion, ciklosporin, teofyllin

- Stoffmisbruk, for eksempel kokain, amfetamin

gamma-GT og karbohydratfattig transferrin (carbohydrate-deficiency transferrin, CDT).

EKG bør også tas rutinemessig for eventuelt å avdekke underliggende hjertesykdom.

Spinalvæskeundersøkelse bør vurderes dersom pasienten har feber, sløret bevissthet og/eller det er mistanke om nakkestivhet. Som oftest tas cerebral CT akutt for å avklare om det foreligger for eksempel hematomer eller intrakraniale svulster. I tillegg bør det i løpet av de nærmeste fire ukene tas cerebral MR for å påvise eventuelle andre strukturelle lesjoner som gir økt risiko for nye anfall $(24,25)$

Epileptiform aktivitet i EEG er assosiert med økt risiko for nye anfall, og standardEEG bør alltid tas (25). Sjansen for å fange opp epileptiform aktivitet er større jo tidligere etter anfallet undersøkelsen gjøres, helst innen 24-48 timer (24, 26, 27). King og medarbeidere fant epileptiform aktivitet hos $51 \%$ av 156 pasienter som fikk utført EEG innen 24 timer etter deres førstegangsanfall, mot hos $34 \%$ av 144 pasienter som fikk tatt EEG på et senere tidspunkt (26). Hos dem som hadde normalt standard-EEG, viste søvndeprivert EEG epileptiform aktivitet hos $35 \%$.

Schreiner og medarbeidere fant at standard-EEG var unormalt hos $70 \%$ av 157 pasienter som fikk EEG-undersøkelse innen 48 timer etter et førstegangs uprovosert anfall. Selv om ikke alle disse fikk påvist sikker epileptiform aktivitet, var et unormalt EEG signifikant assosiert med økt risiko for nye anfall. 60 pasienter fikk i tillegg et søvndeprivert EEG, og det ble påvist epileptiform aktivitet hos $13 \%$ av dem som ikke hadde slik aktivitet i standard-EEG (27).

Et unormalt EEG tatt kort tid etter et førstegangs krampeanfall kan brukes som pre- 
diktor for nye anfall. Dette gjelder særlig dersom kurven viser fokal epileptiform aktivitet. Enkelte studier gir støtte til at søvndeprivert EEG kan gi verdifull tilleggsinformasjon når det gjelder syndromklassifisering og det å anslå risikoen for nye anfall (24).

$\mathrm{Vi}$ mener at alle pasienter med et førstegangs uprovosert krampeanfall bør ha standard-EEG, aller helst i løpet av det første døgnet etter anfallet. Dersom kurven er normal eller kun viser uspesifikke forstyrrelser, anbefaler vi å supplere med søvndeprivert EEG.

\section{Behandling og prognose}

Ved provoserte anfall vil behandlingen avhenge av årsaken. Provoserte anfall er ofte enkeltstående. Risikoen for nye anfall blir borte når den utløsende provoserende faktoren ikke lenger er til stede, og dette kan i mange tilfeller unngås ved å ta forholdsregler. Eksempler på dette er alkoholrelaterte anfall og noen tilfeller av anfall knyttet til medikamentbruk eller metabolske forstyrrelser.

Det diskuteres om man bør starte behandling med antiepileptika etter ett førstegangs uprovosert anfall. Som ellers må man veie fordeler mot ulemper. Hos den enkelte pasient må man med andre ord veie risikoen for nye anfall på kort og lang sikt mot faren for bivirkninger og deres betydning for livskvaliteten.

Ved en systematisk gjennomgang av flere studier av pasienter med et førstegangs uprovosert krampeanfall er det funnet at snaut $50 \%$ av disse ikke får nye anfall (28). Risikoen er størst i perioden like etter det første anfallet, og 80-90\% av dem som făr nye anfall, får dette innen to år $(21,29,30)$. Marson og medarbeidere sammenliknet pasienter som startet med antiepileptika etter førstegangsanfall med pasienter der man ventet med behandling til de fikk anfall nummer to. Behandling etter første anfall reduserte risikoen for nye anfall de neste 1-2 årene, men på lengre sikt var det ingen signifikant forskjell når det gjaldt sjansen for anfallsfrihet. Etter to år var fordelene med god anfallskontroll veid opp av uønskede bivirkninger, og det var ingen forbedring av livskvaliteten (31).

Etter to uprovoserte krampeanfall, derimot, er risikoen for nye anfall mer enn $60 \%$ (32). Vi anbefaler derfor å vente med oppstart av behandling til personen har hatt to uprovoserte anfall. Hos pasienter med fokal anfallsstart, fokalnevrologiske utfall, epileptiforme forstyrrelser i EEG og/eller en påvist epileptogen lesjon ved MR kan det imidlertid være hensiktsmessig å starte behandling allerede etter ett førstegangs krampeanfall (33).

\section{Konklusjon}

Pasienter med førstegangs generalisert toniskklonisk krampeanfall er en heterogen gruppe. I mange studier på dette feltet har man kun sett på pasienter med uprovoserte anfall. Vi mener det er behov for flere studier for å finne ut mer om forekomst, årsaker og utløsende faktorer ved både provoserte og uprovoserte anfall. På denne måten kan vi forbedre diagnostikken, skreddersy behandlingen og gi mer kunnskapsbasert informasjon om risikoen for nye anfall hos den enkelte pasient.

\section{Martha Seim Realfsen (f. 1983)}

er lege i spesialisering i nevrologi.

Forfatter har fylt ut ICMJE-skjemaet og oppgir ingen interessekonflikter.

\section{Siri Hylleraas Bø (f. 1960)}

er ph.d. og overlege.

Forfatter har fylt ut ICMJE-skjemaet og oppgir ingen interessekonflikter.

\section{Morten Lossius (f. 1962)}

er dr.med., spesialist i nevrologi og overlege. Han er leder av forskningsgruppen Kompleks epilepsi ved Oslo universitetssykehus. Forfatter har fylt ut ICMJE-skjemaet og oppgir følgende interessekonflikter: Han har mottatt honorar fra Advisory board perampanel (fycompa) AED Eisai.

\section{Karl O. Nakken (f. 1945)}

er dr.med., spesialist i nevrologi med spesialkompetanse innen epilepsi og medisinsk fagsjef. Forfatter har fylt ut ICMJE-skjemaet og oppgir ingen interessekonflikter.

\section{Litteratur}

1. Modi AC, King AS, Monahan SR et al. Even a single seizure negatively impacts pediatric health-related quality of life. Epilepsia 2009: 50:2110-6.

2. Blume WT, Lüders HO, Mizrahi E et al. Glossary of descriptive terminology for ictal semiology: repor of the ILAE task force on classification and terminology. Epilepsia 2001; 42: 1212-8

3. Wiebe S, Téllez-Zenteno JF, Shapiro M. An evidence-based approach to the first seizure. Epilepsia 2008; 49 (suppl 1): 50-7.

4. Beghi E, Carpio A, Forsgren $L$ et al. Recommendation for a definition of acute symptomatic seizure. Epilepsia 2010; 51: 671-5.

5. McLauchlan DJ, Powell R. Acute symptomatic seizures. Pract Neurol 2012; 12: 154-65.

6. Guidelines for epidemiologic studies on epilepsy. Commission on Epidemiology and Prognosis, International League Against Epilepsy. Epilepsia 1993; 34: 592-6.

7. Hauser WA, Beghi E. First seizure definitions and worldwide incidence and mortality. Epilepsia 2008; 49 (suppl 1): 8-12.

8. Loiseau J, Loiseau P, Guyot M et al. Survey of seizure disorders in the French southwest. I. Incidence of epileptic syndromes. Epilepsia 1990; 31: $391-6$.

9. Annegers JF, Hauser WA, Lee JR et al. Incidence of acute symptomatic seizures in Rochester, Minnesota, 1935-1984. Epilepsia 1995; 36: 327-33.

10. Fisher RS, Acevedo C, Arzimanoglou A et al. ILAE official report: a practical clinical definition of epilepsy. Epilepsia 2014; 55: 475-82
11. Herman ST. Single Unprovoked Seizures. Curr Treat Options Neurol 2004; 6: 243-55.

12. Lawn N, Lieblich S, Lee J et al. Are seizures in the setting of sleep deprivation provoked? Epilepsy Behav 2014; 33: 122-5.

13. Olafsson $E$, Ludvigsson $P$, Gudmundsson $G$ et al. Incidence of unprovoked seizures and epilepsy in Iceland and assessment of the epilepsy syndrome classification: a prospective study. Lancet Neurol 2005; 4: 627-34

14. Hauser WA, Annegers JF, Kurland LT. Incidence of epilepsy and unprovoked seizures in Rochester Minnesota: 1935-1984. Epilepsia 1993; 34: 453-68.

15. MacDonald BK, Cockerell OC, Sander JW et al. The incidence and lifetime prevalence of neurological disorders in a prospective community-based study in the UK. Brain 2000; 123: 665-76.

16. Forsgren L, Bucht G, Eriksson S et al. Incidence and clinical characterization of unprovoked seizures in adults: a prospective population-based study. Epilepsia 1996; 37: 224-9.

17. Jallon P, Goumaz M, Haenggeli $C$ et al. Incidence of first epileptic seizures in the canton of Geneva, Switzerland. Epilepsia 1997; 38: 547-52.

18. Leone M, Bottacchi E, Beghi E et al. Risk factors for a first generalized tonic-clonic seizure in adult life. Neurol Sci 2002; 23: 99-106

19. Leone M, Bottacchi E, Beghi E et al. Alcohol use is a risk factor for a first generalized tonic-clonic seizure. The ALC.E. (Alcohol and Epilepsy) Study Group. Neurology 1997; 48: 614-20.

20. Group CAROLE. Délais évolutifs des syndromes épileptiques avant leur diagnostic: résultats descriptifs de l'enquête CAROLE. Rev Neurol (Paris) 2000; 156: 481-90

21. Berg AT. Risk of recurrence after a first unprovoked seizure. Epilepsia 2008; 49 (suppl 1): 13-8.

22. Brodtkorb E. Common imitators of epilepsy. Acta Neurol Scand Suppl 2013; 127: 5-10.

23. Smith PE. Epilepsy: mimics, borderland and chameleons. Pract Neurol 2012; 12: 299-307.

24. Pohlmann-Eden B, Newton M. First seizure: EEG and neuroimaging following an epileptic seizure. Epilepsia 2008; 49 (suppl 1): 19-25

25. Krumholz A, Wiebe S, Gronseth $G$ et al. Practice Parameter: evaluating an apparent unprovoked first seizure in adults: report of the Quality Standards Subcommittee of the American Academy of Neurology and the American Epilepsy Society. Neurology 2007; 69: 1996-2007.

26. King MA, Newton MR, Jackson GD et al. Epileptology of the first-seizure presentation: a clinical. electroencephalographic, and magnetic resonance imaging study of 300 consecutive patients. Lancet 1998; 352: 1007-11.

27. Schreiner A, Pohlmann-Eden B. Value of the early electroencephalogram after a first unprovoked seizure. Clin Electroencephalogr 2003; 34: 140-4.

28. Berg AT, Shinnar S. The risk of seizure recurrence following a first unprovoked seizure: a quantitative review. Neurology 1991; 41: 965-72.

29. Annegers JF, Shirts SB, Hauser WA et al. Risk of recurrence after an initial unprovoked seizure. Epilepsia 1986; 27: 43-50.

30. Hauser WA, Rich SS, Annegers JF et al. Seizure recurrence after a 1st unprovoked seizure: an extended follow-up. Neurology 1990; 40: 1163-70.

31. Marson A, Jacoby A, Johnson A et al. Immediate versus deferred antiepileptic drug treatment for early epilepsy and single seizures: a randomised controlled trial. Lancet 2005: 365 : 2007-13.

32. Hauser WA, Rich SS, Lee JR et al. Risk of recurrent seizures after two unprovoked seizures. N Engl J Med 1998; 338: 429-34.

33. Marson AG. When to start antiepileptic drug treatment and with what evidence? Epilepsia 2008: 49 (suppl 9): 3-6. 